\title{
IDENTIDADES, INTERCULTURALIDADE E EDUCAÇÃO: UMA ANÁLISE ANTROPOLÓGICA
}

\author{
Ricardo Vieira \\ Professor Coordenador Principal \\ ESECS-IPLeiria / CICS.NOVA.IPLeiria.pt \\ rvieira@ipleiria.pt
}

\section{Resumo}

Três ideias estruturam este texto:

1 - A educação é mais que escolarização. Se o sentido corrente da palavra Educação remete o ensino e a aprendizagem para o domínio das aulas e das escolas, a verdade é que a escolarização dá às crianças e jovens pequeno contributo para a inculturação e construção identitária.

2 - O social e o individual passam pelo indivíduo, não apenas o indivíduo pelos contextos, tornando-o múltiplo, plural, mestiço, construído em continuidades e descontinuidade numa educação intercultural.

3 - A Mediação Intercultural, assente em referência da Pedagogia Social, distanciando-se da pura resolução de conflitos e posicionando-se numa perspetiva preventiva; mas, também, e essencialmente, transformadora das relações sociais, procura mudar situações sociais que geram injustiças, carências ou revoltas, sempre com o envolvimento dos implicados, como busca da convivência num processo educativo intercultural.

Palavras-chave: Educação; identidades; mestiçagem; interculturalidade.

\begin{abstract}
Three key ideas structured this text:

1 - Education is more than schooling. If the current sense of the word refers education teaching and learning for the domain classes and schools, the truth is that education gives children and young people a small contribution to the inculturation and identity construction. 2 - The social and the individual pass by the individual, not just the individual by contexts, making multiple, plural, mestizo, built in continuities and discontinuities in intercultural education.
\end{abstract}




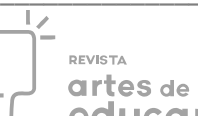

3 - The Intercultural Mediation, based on a framework of social pedagogy, moving away from the pure conflict resolution and positioning a preventive perspective but also, and essentially transforming social relations, seeks to change social situations that generate injustice, shortages or revolts, always with the involvement of those involved, as achieve peaceful coexistence in an intercultural educational process.

Keywords: Education; identities; "Metissage"; interculturality.

\section{IDENTIDADES, INTERCULTURALIDADE E EDUCAÇÃO: UMA ANÁLISE ANTROPOLÓGICA}

\section{A Antropologia das pessoas}

Como sabemos, a educação não remete apenas para a escola. A educação é muito mais que a escolarização. Mas tantas vezes nos esquecemos da amplitude deste processo. Se o sentido corrente da palavra Educação remete o ensino e a aprendizagem para o domínio das aulas e das escolas, a verdade é que a Antropologia da Educação há muito que sublinhou que a escolarização dá às crianças e jovens apenas um pequeno contributo para a inculturação e construção identitária. Como refere Bruner, um psicólogo cultural com grande proximidade à antropologia de Geertz, “Aprender, recordar, falar, imaginar, tudo isto é possibilitado através da construção numa cultura" (BRUNER, 2000, p. 11). E a criança não cai de pára-quedas na escola. A criança que chega à escola já tem todo um percurso de construção cultural que lhe dá um entendimento para a vida e uma epistemologia com a qual se senta como aluno nas cadeiras da escola (ITURRA, 1990a e b).

A Antropologia da Educação que aqui se preconiza não se identifica, ainda assim, apenas pelo uso da etnografia em contextos educativos na escola, fora da escola, na família, nos tempos livres, etc. Com a Antropologia da Educação e suas metodologias hermenêuticas, pretendemos, também, compreender as metamorfoses culturais que ocorrem na vida das pessoas, nas suas identidades pessoais, em consequência das convergências e divergências dos trajetos de vida face à(s) cultura(s) de origem. Assume, pois, a ideia já não tanto de uma antropologia das culturas mas, também, de uma antropologia das pessoas, elas próprias processos culturais em auto e heteroconstrução/reconstrução de si mesmas e da imagem que dão para os outros. Por isso dou ênfase, neste texto, ao estudo de alunos e professores através das suas biografias educativas para compreender como se tornaram naquilo que são (VIEIRA, 


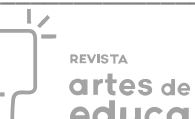

1999a; VIEIRA, 1999b; 2009) e como contributo para uma formação reflexiva para a diversidade cultural e para a interculturalidade (VIEIRA, 2011).

\section{A Educação como processo global e ontológico}

Durante a sua história de vida e seu processo de socialização e educação, que pode ser mais ou menos heterogéneo conforme as esferas culturais, o indivíduo não desempenha apenas um papel que lhe é absolutamente exterior. Daí a importância da captação das subjetividades dos sujeitos estudados desse ponto de vista "émico", interior, que já propunha Malinowski quando nos propôs a observação participante como técnica fundamental do trabalho etnográfico. Daí a importância da escuta do outro, do outro aluno; do outro professor; do outro mãe; do outro pai; dessas vozes todas, para que a educação, mesmo a escolar, seja contextualizada, transformadora de identidades mas sempre na perspetiva da mestiçagem cultural, da interculturalidade e nunca no centramento exclusivo da cultura de partida ou da cultura de chegada.

A Antropologia da Educação assenta num paradigma essencialmente interpretativo, semiológico e hermenêutico, onde a etnografia, a entrevista etnográfica e etnobiográfica, as (auto)biografias, a auto reflexão, os diários e as histórias de vida são vias fundamentais para compreender os processos educativos, de enculturação, aculturação e transmissão cultural bem como a (re)construção identitária. Não se trata, assim, com esta perspetiva, de procurar a causa das coisas educativas, ou de fazer previsão ao modo do positivismo reducionista da ciência moderna.

\section{O trabalho reflexivo com estudantes de mestrado da área da formação de professores e educadores de infância}

No pressuposto de que é preciso desenvolver a comparação e a reflexão sobre o quotidiano da sala de aulas, incidentes pedagógicos, tensões e conflitos que emergem nas aulas e na escola; que é preciso colocar várias mentes a pensar coletivamente sobre as mesmas problemáticas, tenho desenvolvido seminários semanais de reflexão sobre o quotidiano das aulas, em particular sobre os incidentes que remetem para a ideia da diversidade cultural na sala de aula e para a necessidade de construção de novos dispositivos pedagógicos para a ação educativa. Tenho usado, até, o livro do Pequeno Príncipe” para mostrar, com outra literatura eventualmente menos percebida como científica, em que 


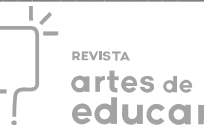

consiste o contacto intercultural e a transformação do self nos processos educativos e na trajetória e da vida de cada sujeito: "O essencial é invisível aos olhos"!

A ideia é mostrar que o social e o cultural não são absolutamente exteriores ao indivíduo; desnaturalizar e "despsicologizar" o conceito de aluno, de pessoa. Efetivamente, o social e o individual passam também pelo indivíduo [não apenas o indivíduo pelos contextos], tornando-o múltiplo, plural, mestiço, construído em continuidades e descontinuidade numa educação intercultural. Continua a tratar-se, efetivamente, de um trabalho antropológico mas que não quer analisar as sociedades e as cultura fora do indivíduo e vice-versa. É legítimo retomar aqui o conceito de bricolage trabalhado por Lévi Strauss (1977), aplicável quer às sociedades e culturas quer às pessoas, que vão fazendo, criando e (re)criando a sua cultura pessoal (VIEIRA, 2009), mista de vários coletivos culturais - os diferentes contextos culturais e linguísticos por onde passam - num processo complexo de auto e heteroconstrução social.

\section{Diálogos e choques de culturas: do Híbrido e do Mestiço na Gestão da Multiculturalidade do Self intercultural}

A propósito do encontro de culturas, de choques culturais e da emergência de novas formas culturais ou de terceiras culturas (VIEIRA, 2009), o conceito de híbrido é, nos contextos anglo-saxónicos, provavelmente mais usado que o de mestiçagem - "métissage" (conceito de origem francesa). Raros são os textos em inglês que usam o conceito de "métissage" ou de Mestizo. Encontramos Anzaldúa (1987) que nos fala de New Mestiza e de Homi (1996) que se refere a este conceito em “Culture's in Between” mas não muito mais. É muito mais usual encontrar-se o conceito de híbrido. Mas o conceito de híbrido remete para uma classificação muito cartesiana em que a normalidade cultural se situa num dos pólos sendo que tudo o que não é nem um nem outro, surge como impuro, híbrido. Mas não há meios-termos na linguagem da complexidade: há terceiros (SERRES, 1993), mestiços, dimensões novas construídas a partir de misturas que mantêm traços de origem, traços de adoção e traços de criação.

Logo, o conceito de mestiçagem, devidamente percebido no contexto das novas análises mais francófonas, remete sim para o intercultural mas nunca para o multiculturalismo que simplesmente tolera as diferenças culturais coexistentes num espaço mas sem promover o diálogo da convivência que leva à mestiçagem e à assunção de um novo paradigma que

Revista Interinstitucional Artes de Educar. Rio de Janeiro, V. 2, N. Especial - pag 164-181 (jun - out 2016): "Vozes da Educação" 
$\int^{-} \begin{aligned} & \text { REVISTA } \\ & \text { artes de } \\ & \text { educa }\end{aligned}$

rompe com a ideia de pureza para mostrar que todas as culturas são dinâmicas, compósitas e mestiças.

O híbrido acaba por ser uma classificação usada por quem tem um olhar monolítico. Claro que Stuart Hall tem este cuidado quando se analisa a si próprio como um híbrido. Ele tem bem consciência da fragilidade do conceito de hibridez (HALL, 1992) que, como é sabido, provém da biologia, tal como o de mestizo, mas que, ao contrário deste, que permite a criatividade (LAPLANTINE et NOUSS, 1997; WIEVIORKA, 2002; SERRES, 1993), o híbrido não se reproduz biologicamente; está condenado à extinção. Por outro lado, também o sincretismo leva à ideia de fusão, de melting pot, o que não corresponde ao paradigma de criatividade pelo encontro cultural nas pessoas, na arte, na música, na pintura, na cultura em geral, onde o todo e as partes coexistem dinamicamente nessa nova totalidade mestiça (LAPLANTINE ET NOUSS, 1997; ANDRÉ, 2005; VIEIRA, 2009).

Quanto ao multiculturalismo (o political correcteness norte-americano, a reivindicação do direito das minorias e das «comunidades étnicas», a apologia do pluralismo terapêutico...), ele é, vê-lo-emos, exatamente o contrário da mestiçagem. Funda-se na coabitação e na coexistência de grupos separados e justapostos, firmemente virados para um passado que convém proteger do encontro com os outros” (LAPLANTINE ET NOUSS, 1997, p. 75).

É claro que o conceito de mestiçagem não pode ser usado ingenuamente:

É certo que, de entre estas noções, o conceito de mestiçagem é o que mais armadilhado se apresenta, quer pela sua génese histórica no contexto de processos de colonização forçada sob o peso, a força e o poder da cruz, das correntes, do chicote, da pólvora e da violação, quer pela possibilidade da sua contaminação, pelo confronto com a noção de pureza a que aparece como contraponto, contaminando maniqueisticamente com um sentido de impuro aquilo a que se refere [...] (ANDRÉ, 2012, p. 95-96).

Contudo, se usado contextualizadamente e com a prudência necessária, e despindo-o das conotações racialistas, assimilacionistas e monistas que não lhe são intrínsecas, não nos parece ser menos adequado, bem pelo contrário, do que outros conceitos que surgem como alternativa, como é o caso de hibridismo. Como refere, ainda, João André, Filósofo de formação mas que tem um trabalho notável, em Portugal, de aproximação à antropologia, à educação intercultural e ao pensamento mestiço,

o conceito de hibridação ou hibridismo tem vindo a ser utilizado por outros autores que olham com reservas para o conceito de «mestiçagem». É o caso, nomeadamente, de Garcia Canclini que, na sua obra Culturas híbridas. Estratégias para entrar y salir de la Modernidade, México, Girijalbo, 1990, prefere esta expressão para caracterizar os processos de misturas 
artes de

educar

interculturais que se verificam atualmente, mas que, simultaneamente, se caracterizam também pela incorporação dos efeitos de histórias e memórias diversificadas (ANDRÉ, 2012, p. 96).

Esta lógica do pensamento mestiço, que se opõe ao pensamento monista dominante, deixa-nos, por vezes, apreensivos. Efetivamente, somos muito o produto do cartesianismo e do positivismo que nos ensinou durante séculos a pensar factualmente e não processualmente; a pensar em estruturas e não em processos. E quando se fala em mestiçagem, não se trata, simplesmente, de juntar, misturar, cruzar, etc. Contudo, ao nível do senso comum, "na medida em que mestiço se contrapõe, habitualmente, a puro, [...] privilegiará, ainda que inconscientemente, o puro como o bom e o mestiço como o contaminado." (ANDRÉ, 2005, p. 126). A mestiçagem deverá ser considerada como algo diferente de justaposição ou de fusão: “ remete para a tensão constitutiva da relação de diferentes, para o dinamismo que ela implica [...] E para a conflitualidade criadora”. (ANDRÉ, 2005, p. 126).

João Maria André sintetiza as mestiçagens em dois grandes grupos:

Se há mestiçagens que se constituem com base no encontro e no diálogo, outras há que resultam da conquista, da violação, do sangue e do sémen misturados num projecto de domínio que é simultaneamente, não poucas vezes, um projecto de exterminação das diferenças e de homogeneização da alteridade. (ANDRÉ, 2005, p. 104).

Quando aplico o conceito de mestiçagem à identidade pessoal e à cultura pessoal, como reiterei atrás, é, justamente, para dar essa ideia não só do "mix" mas, também, como penso que já ficou claro, do processo, do inacabado que é cada sujeito em cada momento da sua história de vida. Não nos podemos pensar como seres estáticos. Há sempre algo que se altera em nós a partir das relações que estabelecemos com o outro. Existem sempre trocas entre ambos. E é dessas trocas com um outro que vamos construindo as nossas próprias aprendizagens (VIEIRA, 2011). Assim, construímos o nosso caminho ao caminhar - através das múltiplas experiências em que vamos participando ao longo da nossa existência - e vai-se (re)construindo a nossa identidade na medida quem que as nossas identificações culturais não são exclusivas nem sempre as mesmas, como é o caso particular do trânsfuga Intercultural (BOURDIEU, 2005; VIEIRA, 2009). Portanto,

[...] nem todos somos feitos de uma só peça, e como observa Amy Gutman, nem toda a gente é tão multicultural como Rushdie, mas as identidades da maior parte das pessoas e não só das elites ou dos intelectuais ocidentais, são formadas por mais do que uma cultura singular. São também as pessoas, e não apenas as sociedades, que são multiculturais." (WIEVIORKA, 2002, p. 23).

Revista Interinstitucional Artes de Educar. Rio de Janeiro, V. 2, N. Especial - pag 164-181 (jun - out 2016): "Vozes da Educação" 
$\mathrm{Na}$ educação, seja escolar ou não escolar, a mediação intercultural e sociopedagógica (VIEIRA A., 2012) surge como uma ferramenta fundamental para gerir tensões sociais e encontros e desencontros culturais para que as mestiçagens possam ser o mais multitópicas possível (VIEIRA A., 2013), como veremos de seguida.

\section{Diversidade Cultural e Mediação Escolar}

Quem não reconhece, hoje, que alguns alunos não se sentem bem na escola, uma vez que esta, tantas vezes, continua "indiferente à diferença"? Alguns alunos questionam-se sobre o sentido da educação que lhes é imposta, fazendo-o muitas vezes de modo turbulento e agressivo.

No entanto, cada vez mais se torna difícil ficar indiferente às diferenças. A abertura da escola a todos, no contexto português em particular, veio criar situações novas, que até aí não eram muito frequentes, mas que hoje fazem parte do quotidiano de muitas escolas. Há hoje alunos com vivências muito diferentes e que foram socializados com diferentes valores, tendo interesses e formas de estar na vida muito diversificados e até opostos aos que a escola monocultural propõe e integra nos currículos. É por isso que é fundamental que os professores tenham atitudes reflexivas e de pesquisa no seu dia-a-dia.

O objetivo da escola de massas é oferecer situações de igualdade de oportunidade a todas as crianças dos diferentes grupos socioculturais. Esta igualdade seria alcançada através de uma oferta educativa igual para toda a população. No entanto, esta igualdade é oferecida a alunos heterogéneos e isto leva a uma desigualdade ao nível de sucessos/insucessos.

Perante este fracasso, vão surgindo orientações educativas para se respeitar a aceitação da diferença. A diferença passou, então, a ser mais valorizada, embora, muitas vezes, apenas nos discursos. Luísa Cortezão, no seu livro "Ser professor: um ofício em extinção? Reflexões sobre as praticas educativas face à diversidade, no limiar do séc XXI" refere que [...] este processo exige que os professores conheçam os seus alunos. Exige que eles tenham estudado as crianças com quem trabalham (recorrendo a diferentes processos simples de observação e pesquisa), e que tenham, portanto, conseguido produzir conhecimento sobre eles, sobre características grupais, socioculturais e até idiossincráticas que eles possuem. (CORTESÃO, 2000, p. 45) 
artes de

educar

De acordo, ainda, com Luíza Cortesão, o professor deixa de ser apenas um instrumento reprodutor de um sistema que o transcende, para a possibilidade de se assumir também como actor interveniente e criador no processo educativo e social. É aqui que emerge a necessidade do modelo de professor multicultural e intercultural. $\mathrm{O}$ aumento da diversidade de públicos originará políticas diversificadas das respostas escolares. Prevê--se diversificação e gestão local do currículo que permita a passagem do ensino uniforme, transmissivo e expositivo, indiferente à diversidade, para um ensino centrado na organização e gestão de situações diferenciadas e interativas de aprendizagem. Esta mudança implica alterações profundas nas formas de trabalhar dos professores.

A atual frequência da escola secundária para todos, em Portugal, tem como consequência direta a transformação dos problemas sociais em problemas escolares (resultantes da pobreza, do desemprego, da desigualdade de classes, toxicodependência, violência juvenil, sida, desestruturação social, exclusão social, etc.). E Isto leva a que se alarguem as funções dos professores tendendo cada vez mais a transformar a profissão de professor como a de um trabalhador social. Pede-se muito à escola e aos professores, responsabilizando-os por tudo.

Vários estudos têm mostrado que talvez o alargamento forçado das funções do professor esteja nas causas do grande mal-estar existente na profissão. Em Portugal, no plano legislativo, (Decreto-lei no 515/99 de 21 de Novembro), reconhece-se que as escolas devem possuir, nos seus quadros, um corpo de profissionais que respondam a esta situação, para além dos professores. Este decreto foi mais tarde revogado, sem que produzisse qualquer efeito. A escola tem mantido uma posição hegemónica e para ver a diferença a partir do lado dos alunos, obrigaria o professor a trabalhar também fora da sala de aula. Alguns conseguem fazê-lo, mas é esse o seu papel?

É muito importante pensar que as diversidades que nos surgem na sala de aulas resultam de diferenças individuais, no sentido psicológico da coisa, mas, também de diferenças pessoais (simultaneamente individuais e grupais), sociais e culturais, o que implica pensar não apenas no aluno, mas na pessoa do aluno, que não está só na escola, mas entre a escola e o lar (VIEIRA, 1992; PERRENOUD, 2001). Contudo, o espírito de abertura da escola à comunidade apregoado pela legislação, obrigaria a outro trabalho que neste texto denominamos mediação escolar. É necessário estabelecer contactos e comunicação com a rede familiar e comunitária do aluno.

Helena Neves Almeida diz: 
1 - $\int_{\text {REVISTA }}^{\text {artes de }}$

Os mediadores profissionais, sobretudo aqueles que do ponto de vista funcional e de competências estão mais próximos dos utentes e do seu contexto geográfico e social de proveniência, desenvolvem esforços de articulação e de promoção de redes de proximidade, articulando redes de solidariedade formal e informal. Estabelecem contactos com familiares, amigos, vizinhos, com aqueles que acompanharam a sua trajectória de vida e que são significativos na relação que eles estabelecem com o meio e consigo próprios, incitando-os à mobilização das suas energias no sentido de ser constituída uma rede de suporte afectivo e social nos momentos de crise e durante o processo de acompanhamento cuja gestão tem de ser feita quotidianamente.

O professor, por muito multifacetado que seja, não está preparado para este tipo de trabalho, embora por vezes o tente fazer por voluntarismo.

É necessário criar condições materiais que permitam às escolas dotar-se de equipas de profissionais sociais (educadores sociais, técnicos de Serviço Social... e não apenas psicólogos) que, em conjunto com os professores, respondam à multiplicidade de solicitações e responsabilidades que são pedidos à escola atualmente.

O futuro da educação escolar parece-nos ter de passar pela mediação escolar e pelas parcerias das escolas com instituições da comunidade educativa. E é também, aqui, que estes profissionais sociais desempenharão um papel fulcral. Claro que Isto implicará um reforço no investimento em recursos humanos afetos aos sistemas de educação públicos.

\section{Competências da Mediação Intercultural como prática da Pedagogia Social}

Urge agora refletir um pouco sobre o que entendemos por mediação e, em particular, por mediação intercultural e por mediação sociopedagógica, como ferramentas didáticas para trabalhar com as diversidades, não isoladamente mas, antes, em interação.

Sempre que se fala em mediação, é comum emergir, em primeiro lugar, a ideia de posição intermédia, da presença do terceiro termo, "o terceiro" que se refere ao mediador como pessoa, ou à equipa que assume a função de ponte, ligação ou catalisador dos processos de mediação. A terceira parte pressupõe e condiciona a existência de duas partes: “A estrutura ternária implica abertura, uma vez que o terceiro rompe a dualidade em que os dois seres se encontram envolvidos" (TORREMORELL, 2008, p. 23) e é para eles um ponto de referência comum.

Efetivamente, a mediação implica a construção de terceiros lugares mas estes não têm, necessariamente, de ser um ponto equidistante entre as partes. Se na mediação jurídica, por 
$\int^{-2} \begin{aligned} & \text { REVISTA } \\ & \text { artes de } \\ & \text { educa }\end{aligned}$

exemplo, esse lugar, que continua a ser uma terceira posição, se cruza com a apregoada imparcialidade, na Mediação Intercultural, que além de preventiva se assume como transformadora da sociedade e como construtora de espaços de (con)vivência, estamos perante um novo paradigma assente na Pedagogia Social. A este propósito, como sublinham Carvalho e Baptista (2004, p. 72),

Os educadores sociais surgem, neste sentido, como mediadores profissionais, como promotores de laços sociais numa perspectiva criativa e renovadora que não se confunde com a conceção de mediação de tipo curativo ou preventivo". Ainda de acordo com estes autores, numa matriz de Pedagogia Social, "mais do que procurar minorar tensões existentes entre indivíduos ou grupos, trata-se de promover relações interpessoais positivas, impulsionadoras de atividade, de criatividade e de solidariedade. [...] Indissociável do sentido transformador evidenciado anteriormente, a mediação pedagógica é necessariamente otimista e ambiciosa. Nessa medida, ela demarca-se das práticas de simples assistência ou ajuda humanitária.

Em segundo lugar, quando se fala de mediação, surge, tanto nos discursos como nos manuais, o grande dogma da neutralidade. A ideia de que é possível o profissional social ser neutro. Contudo, a única forma de ser neutro é estar morto, como nos lembra Torremorel (2008). A necessária empatia que o mediador intercultural tem de desenvolver com as partes envolvidas, enquanto interventor social, não lhe permite a neutralidade axiológica. Relativamente a esta questão da neutralidade, que é um dos aspetos mais polémicos da mediação, fomos assistindo, mais recentemente, à convocação do conceito de imparcialidade, em vez do de neutralidade, embora alguns autores continuem a considerar tal atitude como uma abstração. Há, ainda, autores que em vez de falarem em imparcialidade - não tomar partido por ninguém - passaram a falar em "multiparcialidade" (TORREMORELL, 2008) uma vez que o mediador tem de promover a escuta ativa com todos, tentar entrar no entendimento de todos, e isso não pode ser feito de forma neutral nem imparcial. Tal trabalho implica atitudes empáticas por parte do mediador, e, daí, a ideia da "multiparcialidade":

[...] ou seja , tomar partido por todos. Pensamos que esta ideia é especialmente estimulante, uma vez que fez evoluir um debate que estancou no ponto de saber se é, ou não, possível ser neutro e imparcial, quando é bem evidente que «os mediadores desempenham, inevitavelmente, um papel influente no desenrolar do conflito» (FOLGER E JONES, 1997, p. $305)$.

$\mathrm{O}$ conceito de multiparcialidade evoca, simultaneamente, independência e empatia. $\mathrm{O}$ mediador, pessoa independente em relação aos actores do conflito e ao resultado do mesmo, 
artes de

educor

pode adoptar atitude empáticas - já não neutrais - construtoras de confiança, incorporando uma carga de sinal positivo no desenvolvimento do processo mediado. Segundo esta óptica, actuar como se fossemos neutros seria bastante pobre (TORREMORELL, 2008, p. 24)

Ainda assim, se entendermos a Mediação Intercultural no âmbito da Pedagogia Social e não da mediação em geral que nasce a partir de paradigmas resolutivos da escola de negócios de Harvard, dos anos 50, e, portanto, mais na perspetiva reabilitadora e criativa, que preventiva ou resolutiva, nem é absolutamente de "multiparcialidade" que se trata, apenas. Efetivamente, para facilitar a comunicação, para fomentar a coesão social e promover a autonomia e a inserção social das minorias e dos mais fragilizados, o mediador não pode tomar a parte da cultura hegemónica sob pena de estar a desenvolver um assimilacionismo disfarçado de neutralidade. A autonomização, o empoderamento e a advocacia dos desfavorecidos implicam um mediador intercultural que se demarque da imparcialidade mas também das simples práticas de assistencialismo e de ajuda humanitária.

A Mediação Intercultural, assente num quadro de referência da Pedagogia Social, atravessa, assim, os vários domínios do social e as mais variadas formas de mediação (comunitária, sanitária, escolar, familiar, laboral, jurídica, etc.) distanciando-se da pura resolução de conflitos e posicionando-se numa perspetiva preventiva mas, também, e essencialmente, transformadora das relações sociais. De facto, o mediador intercultural não pode deixar de ser, também, um interventor social e pedagógico que procura mudar situações sociais que geram injustiças, carências ou revoltas, sempre com o envolvimento dos implicados, como busca da convivência (JARES, 2007) e da hospitalidade enquanto valor humano (CARVALHO E BAPTISTA, 2004; PERES, 2010). De alguma forma, é aí que se situa Torremorell que reutiliza o conceito de "multiparcialidade" a partir de Folger e Jones (TORREMORELL, 2008, p. 24). Torremorell vai também mais longe ao caraterizar a competências e o perfil do mediador intercultural:

Chegados a este ponto, poderíamos definir a mediação como um processo ternário em que os participantes, mediador e protagonistas, exploram voluntariamente a situação conflituosa para facilitar uma tomada de decisões conjunta liderada pelos protagonistas (TORREMOREL, 2008, p. 84).

Esta é a perspetiva clássica da mediação, tão associada ao final da linha dos processos de tensão e conflito onde a resolução, a intenção de por termo aos conflitos e divergências é o interesse principal, ainda que tal possa não passar dum sucesso superficial, com a ajuda de 


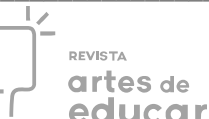

técnicas de comunicação e que apenas levam a um entendimento que acaba poer ser provisório e nada transformativa das identidades dos envolvidos, sejam grupos, comunidades ou indivíduos. O nosso interesse pela mediação vai muito para além das técnicas e centra-se, essencialmente, na relação entre as partes envolvidas e na convicção de que tal interação/comunicação/relação pode ser feita de forma simétrica, sem reféns e sem imposições hegemónicas ou suportadas por fundamentalismos. Por isso, também podemos definir a mediação intercultural

[...] como uma tentativa de trabalhar com o outro e não contra o outro, procurando uma via pacífica para enfrentar os conflitos num ambiente de crescimento, aceitação, aprendizagem e respeito mútuo. [...] A mediação, além do mais, procura equidade e compromisso informado superando a violência, e a exclusão é integrada num amplo movimento personalizador de coesão social. (TORREMORELL, 2008, p. 85).

A Mediação Intercultural atravessa, ou pode atravessar, se se assumir o intercultural como paradigma que rompe com o culturalismo [monoculturalismo], todas as mediações socioculturais (familiar, comunitária, pessoal, laboral, jurídica, escolar, etc.) e não está presente apenas em contextos de forte multiculturalidade, como é o caso evidente da coexistência de pessoas migrantes, como algum senso comum aponta, por vezes (VIEIRA, A., 2013).

Em síntese, agora, toda a Mediação Intercultural é Sociocultural. Toda a Mediação Escolar e Sociopedagógica tem de ser sociocultural porque os sujeitos são seres biopsicossocioculturais. Mas nem todas as mediações socioculturais são, necessariamente, interculturais. A Mediação Intercultural remete, sempre, para a ideia do terceiro lugar, terceira pessoa, mestiçagem, cultura(s) dinâmica(s), interculturalidade e (Trans)formação dos sujeitos e culturas envolvidas, ao invés de culturas consideradas fechadas e engessadas em determinado grupo social.

\section{Interculturalidade, (auto)biografia como (re)descoberta de si e (trans)formação para a educação para a diversidade cultural}

A reflexão intercultural tem estado muito ligada aos problemas das migrações às questões do ensino para imigrantes, problemática dos trabalhadores estrangeiros, etc. (CAMILLERI, 1989). Mas o intercultural não se reduz às relações internacionais e interétnicas (GUSMÃO, 2004). Nas minhas pesquisas no âmbito da antropologia da educação, 
artes de

educar

tenho procurado frisar outra dimensão da reflexão sobre o intercultural. Agora é sobre o contacto interpessoal, que é sempre intercultural, na sala de aulas - onde se constata também a multiculturalidade - e dos sujeitos aí presentes, com experiências, trajetórias, pensamentos, culturas pessoais e grupais, práticas e representações sociais próprios, que reflito na parte final deste texto.

No contacto intercultural, o que se comunica não são verdadeiramente as identidades grupais, as culturais nacionais ou locais mas, antes, as pessoas portadoras duma identidade pessoal, dinâmica, e sempre em gerúndio (VIEIRA, 2009), ela própria multicultural. Até numa visita de estudo da turma a determinado contexto, meio, exposição, ambiente, há sempre diligências pessoais que se podem revestir de aquisições de saberes, descoberta de tradições, paisagens, etc. Mas também se põem em contacto diferentes modos de vida, maneiras de pensar e de sentir próprios de grupos e das pessoas elas mesmas, num processo de interculturalidade.

A heterogeneidade cultural dos grupos é interiorizada, incorporada, de modo idiossincrático, por parte de cada aluno nesses encontros. Cabe ao Professor desempenhar o papel de mediador intercultural (VIEIRA, 2011) e ajudar o aluno a (re)construir o seu eu intercultural, sem ambiguidades, sem grandes conflitos interiores ou receio de receber da alteridade para si. Como nos deixou bem claro Saint-Exupery, "Sou um pouco de todos que conheci, um pouco dos lugares que fui, um pouco das saudades que deixei e sou muito das coisas que gostei $[\ldots]$ ". Mas, por vezes, num mundo que continua a pensar, a ver e a avaliar a preto e branco, de acordo com lógicas binárias e monistas (VIEIRA, 2009), não é fácil que cada um de nós assuma a multiculturalidade em si, a mestiçagem de si (VIEIRA, 2011). Aí, o papel do professor, também ele como investigador e etnógrafo da sua própria escola e turma, como antropólogo dos seus alunos, como contributo para a construção também de crianças interculturais, que podendo ser diferentes, possam, no entanto, comunicar-se. Daí que o professor deva interiorizar a mensagem da antropologia da educação, até ao ponto de sentirse, ele mesmo, um antropólogo. Mas isso exige uma preparação antropológica dos professores, na formação inicial e na formação contínua. Não basta, não é suficiente uma relação professor-aluno empática. É preciso tirar partido da diversidade de contextos para construir práticas pedagógicas interculturais pois "a pedagogia intercultural permite sair da alternativa binária e demasiado simplista: novos objetos, novas didáticas” (ABDALLAHPRETCEILLE, 1990, pp. 215 e 216).

Com vista a esta prática, qualquer professor deve começar por dar um primeiro passo para o desenvolvimento do seu eu pessoal e profissional. "Os professores precisam de ter um 
$\int^{-} \begin{aligned} & \text { REVISTA } \\ & \text { artes de } \\ & \text { educor }\end{aligned}$

sentido muito claro da sua própria identidade étnica e cultural, para poderem compreender a dos seus alunos e respectivas famílias" (ZEICHNER, 1993, pp. 89 e 90) e precisam melhorar os seus conhecimentos e atitudes em relação às diferentes características sócio culturais dos seus alunos. Se não têm competências interculturais há que procurar vias de as desenvolver, como é o caso do caminho que temos proposto com o trabalho (auto)biográfico do próprio docente e dos seus alunos, para potenciar o pensar a aprendizagem do ponto de vista de quem aprende.

É importante que cada profissional social, da educação ou não, tenha um conhecimento comparativo para além das circunstâncias imediatas do seu meio local. Há professores cuja trajetória social lhes deu esse treino de refletir as ações, de pensar o que se está a fazer, e porque se faz assim, e, no tocante aos outros, de procurar entender o seu entendimento. São pessoas que, no quotidiano, acabam por refletir a todo o momento e pôr assim em prática a sua metacognição. Surge então, por continuidade, um conhecimento comparativo dos diferentes meios sociais por parte deste tipo de sujeitos.

Por outro lado, também, há assim, uma melhoria qualitativa do seu próprio conhecimento e do entendimento das suas ações e saberes locais, pois o considerar das relações entre um determinado contexto e o seu ambiente social mais amplo, ajuda a esclarecer o que se passa no próprio contexto. E comparar-se com o outro, que faz de modo diferente, implica, em primeiro lugar, conhecer-se a si próprio, tornar visível as suas práticas e representações sociais correlacionadas com a sua própria biografia que suporta tais atitudes e condutas. Depois, em segundo lugar, implica contactar com a alteridade e perceber as alternativas à monoculturalidade, porventura do seu eu profissional. À partida, o docente, e não só, cai, não raras vezes, na tentação de considerar o que sucede habitualmente na sua vida quotidiana como o modo como efetivamente devem ser as coisas, as práticas e as ideias, para sempre e em todas os espaços. É o etnocentrismo comum a todos os mortais e a todas as culturas que urge ser relativizado. E, por isso, urge pensar, a este propósito, no papel da antropologia da educação na formação inicial mas, também, na formação contínua, sempre, e não apenas para a adequação a uma reforma que se impõe normativamente. E importa pensar numa nova forma de fazer formação contínua, uma forma baseada essencialmente na reflexividade e na investigação: na investigação, por exemplo, das histórias de vida dos alunos que se tem, da própria autobiografia do docente e dos colegas, para se saber quem se é, quem se quer ser e como e quem são os outros. Enfim, uma formação contínua muito baseada, também, na reflexão autobiográfica. 
$\square^{-}$artes de

À medida que se aprende mais acerca do mundo exterior, vai-se aprendendo mais acerca de nós mesmos. Preparar para educar na e para a diversidade, implica o conhecimento e (re)descoberta de si (PINEAU, 1990) e do diálogo da própria multiculturalidade no eu pessoal e profissional.

\section{Notas finais}

Penso ter ficado clara a importância do uso compreensivo de narrativas biográficas e de histórias de vida como um caminho metodológico, de cariz etnográfico, fundamental para compreender como a realidade social exterior se incorporou no self que se torna pluricultural/mestizo com inúmeras possibilidades de gestão das suas pertenças. Como explicita Pierre Bourdieu, no livro que dá conta do seu último curso no Collège de France, onde se submete a si mesmo ao exercício da reflexividade, "compreender é, em primeiro lugar, compreender o campo em que nos fizemos e contra o qual nos fizemos" (BOURDIEU, 2005, p. 15).

Nesta via investigativa, o investigador preocupa-se em compreender detalhadamente e aprofundadamente o que é que os sujeitos pensam, como é que desenvolvem os seus quadros de referência e como é que se apresentam no quotidiano e gerem as suas várias identidades pessoais ou pertenças identitárias.

A narrativa é uma condição ontológica da vida social, pois é através dela que o sujeito se reinventa, articulando, no presente, factos passados e projetos futuros. A narrativa biográfica é aqui vista como uma ferramenta poderosa para dar conta do processo de "métissage" cultural ou de interculturalidade. As identidades são, assim, construídas na e pelas narrativas enquanto discurso reflexivamente organizado, e é desta forma que os sujeitos se apresentam nas relações sociais. As narrativas, no campo das ciências antropológicas e da Educação, na interpretação interativa com os seus atores, constituem uma revolução metodológica, contra a tecnocracia positivista, que permite a emergência de um conhecimento fundamentado sobre uma subjetividade consciente de si mesma e, por outro lado, um conhecimento experiencial que valoriza a reflexividade produzida a partir de vivências singulares.

Considerando a metáfora produzida por Michel Serres no seu livro O Terceiro Instruído (1993), embora nasçamos numa margem do rio, esse lugar inicial do eu pessoal e social não corresponderá a todos os lugares que o sujeito habitará no seu percurso de vida em consequência das várias aprendizagens e identificações . A transformação social de cada sujeito, produzida pelos processos educativos em que participa, é ininterrupta: cada 


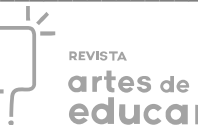

aprendizagem é transformação; é espaço de mestiçagem e interculturalidade. Ninguém é apenas de um lugar. E, sendo os sujeitos do mundo contemporâneo cada vez mais educados em contextos multiculturais, urge compreender como cada um se forma e se identifica.

Por outro lado, toda a transformação/ viagem cultural abre portas a transformações identitárias dos sujeitos, criando ambivalências, completudes, sobreposições e dualismos identitários. Convém dizer que se este processo de transformação e de identidade em gerúndio (VIEIRA, 2009) é, provavelmente, bem entendível com populações migrantes, a verdade é que estas metamorfoses culturais ocorrem também com pessoas não migrantes. A entrada para o mundo da escola pode ser, para alguns jovens, um bom exemplo de como pensar aqui a reconstrução pessoal e cultural como um processo migratório cognitivo e identitário. Também aqui, quanto mais contrastantes forem as esferas culturais vivenciadas pelos indivíduos, mais visíveis se tornam estes fenómenos para si e para os outros e mais complexa se pode tornar a gestão identitária entre o modelo extremos que renega as origens, e o modelo do trânsfuga intercultural, o modelo utópico da assunção de toda a mestiçagem cultural e da comunicação e identificação com todas as culturas atravessadas e incorporadas.

\section{Referências}

ABDALLAH-PRETCEILLE, M. Vers une Pedagogie Interculturelle, Paris: INRP. 1990.

ALMEIDA, H. N. "A recomposição dos laços sociais - uma mediação expressiva e instrumental na luta contra a exclusão social" in CUNHA, Pedro (org.) (2004), Actas do colóquio de mediação. Uma forma de resolução alternativa de conflitos, Porto, Universidade Fernando Pessoa. 2004.

ANDRÉ, J. Diálogo Intercultural, Utopia e Mestiçagem em Tempos de Globalização. Coimbra: Ariane Editora. 2005.

ANDRÉ, J. Multiculturalidade, Identidades e Mestiçagem: O Diálogo Intercultural nas Ideias, na Política, nas Artes e na Religião. Coimbra: Palimage. 2012.

ANZALDÚA, G. Borderlands/La Frontera: The New Mestiza. San Francisco: Aunt Lute Books. 1987.

BOURDIEU, P. Esboço para uma Auto-análise, Lisboa: Edições 70. 2005.

BRUNER, J. Cultura e Educação, Lisboa: Ed. 70. 2000.

CAMILlERI, C. ; COHEN-EMERIQUE, M. (Dir.). Chocs des Cultures; Concepts et Enjeux Pratiques, Paris: L’ Harmattan. 1989. 


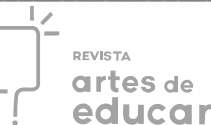

CARVAlHO, A. \& BAPTISTA, I. Educação Social, Fundamentos e Estratégias, Porto:

Porto Editora. 2004.

CORTESÃO, L. Ser professor: um ofício em extinção? Reflexões sobre as praticas educativas face à diversidade, no limiar do séc XXI, Porto, Edições Afrontamento. 2000.

GUSMÃo, N. M. M. Os filhos da África em Portugal, Antropologia, multiculturalidade e educação. Lisboa: Imprensa de Ciências Sociais. 2004.

HALL, S. "The Question of Cultural Identity", D. Hall \& A. McGrew (eds.), Modernity and Its Futures. Cambridge: Polity Press, 1992. pp. 274-316.

ITURRA, R. Fugirás à Escola para Trabalhar a Terra: Ensaios de Antropologia Social sobre o Insucesso Escolar, Lisboa: Escher. 1990a.

ITURRA, R. A Construção social do insucesso escolar, Lisboa: Escher. 1990b.

JARES, X. Pedagogia da Convivência. Porto: Profedições. 2007.

LAPLANTINE, F. e NOUSS, A. A Mestiçagem, Lisboa: Instituto Piaget. 1997.

LEVI-STRAUSS, C. (ed.) L'Identité. Paris: Grasset. 1977.

PERES, A. "Introdução" in PERES, Américo e VIEIRA, Ricardo (Orgs.). Educação, Justiça e Solidariedade na Construção da Paz, Chaves e Leiria: APAP e CIID-IPL, 2010. pp. 9-29.

PERRENOUD, P. A Pedagogia na escola das Diferenças, Porto Alegre: Artmed. 2001.

PINEAU, G. "Les histoires de vie en formation: un mouvement socio-educatif", Le Groupe Familiale, $\mathrm{n}^{\circ}$ 126. 1990.

SERRES, M. O Terceiro Instruido. Instituto Piaget: Lisboa. 1993.

TEODORO, A. Professores para quê? Mudanças e desafios na profissão docente, Porto: Profedições. 2006.

TORREMOREL, M. Cultura de Mediação e Mudança Social, Porto: Porto Editora. 2008.

VIEIRA, A. "Pedagogia social nas escolas: um olhar sobre a mediação e a educação social" in Cadernos de Pedagogia Social,nº 4, Porto: Universidade Católica, 2012. pp 9-26.

VIEIRA, R. Histórias de Vida e Identidades: Professores e Interculturalidade, Porto: Afrontamento. 1999a.

VIEIRA, R. Ser igual Ser Diferente: Encruzilhadas da Identidade, Porto: Profedições. 1999b.

VIEIRA, R. "Vidas revividas: etnografia, biografias e a descoberta de novos sentidos", in CARIA, Telmo (Org.) (2003). Metodologias Etnográficas em Ciências Sociais, Porto: Afrontamento, 2003. pp. 77-96.

VIEIRA, R. Identidades Pessoais. Interacções, Campos de Possibilidade e Metamorfoses Culturais, Lisboa: Colibri. 2009. 
VIEIRA, R. Educação e Diversidade Cultural: notas de antropologia da educação, Porto:

Ed. Afrontamento. 2011.

VIEIRA, R. Entre a Escola e o Lar: o currículo e os saberes da infância, Lisboa: Escher. 1992.

WIEVIORKA, Michel A Diferença, Lisboa: Fenda Edições. 2002.

ZEICHNER, K. A Formação Reflexiva de Professores: Ideias e Práticas, Lisboa: Educa. 1993.

\section{Webgrafia}

http://www.acm.gov.pt/-/resmi-rede-de-ensino-superior-para-a-mediacao-intercultural acedido em 18 de fevereiro de 2016. 